General Thoracic

Surgery

\title{
Predictors of operative mortality and cardiopulmonary morbidity in the National Emphysema Treatment Trial
}

\author{
Keith S. Naunheim, MD, ${ }^{a}$ Douglas E. Wood, MD, ${ }^{\mathrm{b}}$ Mark J. Krasna, MD, ${ }^{\mathrm{c}}$ Malcolm M. DeCamp, Jr, MD, \\ Mark E. Ginsburg, MD, ${ }^{\mathrm{e}}$ Robert J. McKenna, Jr, MD, ${ }^{\mathrm{f}}$ Gerard J. Criner, MD, ${ }^{g}$ Eric A. Hoffman, PhD, \\ Alice L. Sternberg, ScM, and Claude Deschamps, MD, ${ }^{j}$ for the National Emphysema Treatment Trial Research Group
}

Earn CME credits at http://cme.ctsnetjournals.org

From the Division of Cardiothoracic Surgery, St Louis University Health Sciences Center, ${ }^{\mathrm{a}} \mathrm{St}$ Louis, Mo; the University of Washington, and the Cost-Effectiveness Data Center, Fred Hutchinson Cancer Research Center, ${ }^{\mathrm{b}}$ Seattle, Wash; the University of Maryland at Baltimore and Johns Hopkins Hospital, ${ }^{\mathrm{c}}$ Baltimore, Md; Cleveland Clinic Foundation, ${ }^{\mathrm{d}}$ Cleveland, Ohio; Columbia University, New York, and Long Island Jewish Medical Center, ${ }^{\text {e New }}$ Hyde Park, NY; Cedars-Sinai Medical Center, ${ }^{f}$ Los Angeles, Calif; Temple University Medical Center, ${ }^{\mathrm{g}}$ Philadelphia, Pa; CT Scan Image Storage and Analysis Center, University of Iowa, ${ }^{\text {h }}$ Iowa City, Iowa; Coordinating Center, Johns Hopkins University, ${ }^{i}$ Baltimore, Md; and the Mayo Foundation, ${ }^{\mathrm{j}}$ Rochester, Minn.

The National Emphysema Treatment Trial is supported by the National Heart, Lung, and Blood Institute (contracts N01HR76101, N01HR76102, N01HR76103, N01HR76104, N01HR76105, N01HR76106, N01HR76107, N01HR76108, N01HR76109, N01HR76110, N01HR76111, N01HR76112, N01HR76113, N01HR76114, N01HR76115, N01HR76116, N01HR76118, and N01HR76119); the Centers for Medicare and Medicaid Services; and the Agency for Healthcare Research and Quality.

Read at the Eighty-fifth Annual Meeting of The American Association for Thoracic Surgery, San Francisco, Calif, April 10-13, 2005.

Received for publication April 12, 2005; revisions received Sept 4, 2005; accepted for publication Sept 9, 2005.

Address for reprints: Keith S. Naunheim, MD, Division of Cardiothoracic Surgery, St Louis University Health Sciences Center, 3635 Vista Ave, St Louis, MO 63110-0250 (E-mail: naunheim@slu.edu).

J Thorac Cardiovasc Surg 2006;131:43-53

$0022-5223 / \$ 32.00$

Copyright (C) 2006 by The American Association for Thoracic Surgery

doi:10.1016/j.jtcvs.2005.09.006
Objective: We sought to identify predictors of operative mortality, pulmonary morbidity, and cardiovascular morbidity after lung volume reduction surgery.

Methods: Univariate and multivariate logistic regression analyses were performed. Candidate predictors included demographic characteristics, physical condition characteristics, pulmonary function measures, measures of the distribution of emphysema as determined by radiologists and by means of computerized analysis of chest computed tomographic scans, and measures of exercise capacity, dyspnea, and quality of life. End points analyzed were operative mortality (death within 90 days of the operation), major pulmonary morbidities (tracheostomy, failure to wean, reintubation, pneumonia, and ventilator for $\geq 3$ days), and cardiovascular morbidities (infarction, pulmonary embolus, or arrhythmia requiring treatment).

Results: Five hundred eleven patients in the non-high-risk group of the National Emphysema Treatment Trial underwent lung volume reduction. The incidence of operative mortality was $5.5 \%$, major pulmonary morbidity occurred in $29.8 \%$ of patients, and cardiovascular morbidity occurred in $20.0 \%$ of patients. Predictors for these end points are as follows:

\begin{tabular}{llcc}
\hline & & Relative odds & $P$ value \\
\hline Operative mortality & $\begin{array}{l}\text { Non-upper-lobe predominance } \\
\text { (radiologist) }\end{array}$ & 2.99 & .009 \\
Pulmonary morbidity & Age in years & 1.05 & .02 \\
& FEV \% predicted & 0.97 & .05 \\
& DLCo \% predicted & 0.97 & .01 \\
Cardiovascular morbidity & Age in years & 1.07 & .004 \\
& Oral steroid use & 1.72 & .04 \\
& Non-upper-lobe predominance & 2.67 & $<.001$ \\
& (OIA $\alpha$ measure) & &
\end{tabular}

$F E V_{1}$, Forced expiratory volume in 1 second; DLCO, diffusion capacity; $Q I A$, quantitative image analysis.

Conclusions: Although lung volume reduction can be performed in selected patients with acceptable mortality, the incidence of major cardiopulmonary morbidity remains high. The lone predictor for operative mortality of lung volume reduction was the presence of non-upper-lobe-predominant emphysema, as assessed by the radiologist. Pulmonary morbidity can be expected in elderly patients who have a low diffusing capacity for carbon monoxide and forced expiratory volume in 1 second. When assessing morbidity, the computer-assisted chest computed tomographic analysis proved useful only in predicting cardiovascular complications. 

Abbreviations and Acronyms
$\mathrm{CT}=$ computed tomography
DLCO = diffusing capacity for carbon monoxide
$\mathrm{FEV}_{1}=$ forced expiratory volume in 1 second
$\mathrm{HU}=$ Hounsfield unit
LVRS $=$ lung volume reduction surgery
NETT $=$ National Emphysema Treatment Trial
QIA = quantitative image analysis
$\mathrm{RO}=$ relative odds
$\mathrm{UCSD}=$ University of California San Diego

工

ung volume reduction surgery (LVRS) has been demonstrated to be beneficial in selected patients with severe emphysema. ${ }^{1}$ However, because of the fragile nature of patients with severe emphysema, surgical morbidity and mortality remain higher than for most other elective thoracic surgical procedures. Reported operative mortalities have ranged from $4 \%$ to as high as $14 \%$, whereas the incidence of pulmonary complications, such as pneumonia, reintubation, and ventilator dependence, are also reported to be higher than that observed for most other commonly performed thoracic procedures. ${ }^{2,3}$

Previous studies have proposed several demographic, pulmonary, and cardiovascular physiologic and/or radiographic features predictive of excessive morbidity in patients undergoing LVRS. ${ }^{4-9}$ It was hoped that identification of factors that portend high morbidity might lead to the exclusion of patients from consideration for LVRS, or alternatively, practitioners might be alerted to specific risks and take steps to avoid predicted complications. However, these studies yield conflicting results about which factors are predictive of morbidity, and uncertainty still remains regarding the validity of their predictions. Unfortunately, virtually all of these studies have serious limitations, including small patient numbers, selection bias, institutional bias, and incomplete or suboptimal data collection.

The National Emphysema Treatment Trial (NETT), a large, prospective, randomized, multicenter, long-term trial comparing optimum medical therapy with optimum therapy plus LVRS was conceived and designed to provide more definitive answers regarding not only the value of LVRS but also optimal patient selection. A prior NETT publication sought to establish the efficacy of LVRS and to identify factors predictive of midterm to long-term survival, as well as functional outcome. ${ }^{1}$ The purpose of this article is to extend the findings of these prior reports and specifically identify predictors of short-term mortality and morbidity after LVRS in the NETT population, including operative mortality and major cardiopulmonary complications.

\section{Materials and Methods \\ Study Design}

The designs and methods of the NETT have been fully described in a prior publication but will be reviewed briefly. ${ }^{10}$ Patients with severe emphysema underwent thorough medical evaluation to confirm the presence of severe emphysema and overall fitness for potential LVRS candidacy. These evaluations were undertaken at 17 NETT clinical centers throughout the country that had been selected by the National Heart, Lung, and Blood Institute. Baseline measurements included collection of demographic data, postbronchodilator spirometry, lung volume plethysmographic assessment, chest computed tomography (CT), split ventilation-perfusion nuclear imaging, standard anteroposterior and lateral chest radiography, cardiovascular assessment (routine dobutamine stress tests and echocardiography), and exercise capacity, as measured both by means of a standardized 6-minute walk and formal maximum symptom-limited cycle ergometry with graded exercise loading and oxygen supplementation. In addition, patients underwent assessment of their subjective well-being by using questionnaires regarding dyspnea (University of California San Diego [UCSD] Shortness of Breath Questionnaire and St George's Respiratory Questionnaire) and quality of life (Quality of Well Being scale and SF-36 short form questionnaire).

\section{Diagnostic Imaging Studies}

The distribution of emphysema was determined by using several methodologies. Initially, it was classified as heterogeneous or homogeneous on the basis of the high-resolution CT scan by using a visual scoring system in which the radiologist had been trained and certified. The radiologist also classified the craniocaudal distribution of emphysema as affecting predominantly the upper lobes (upper-lobe-predominant disease), or it was reported as mainly involving the lower lobes, the superior segment of the lower lobes, or the lungs. These latter 3 classifications were grouped together under the heading of non-upper-lobe emphysema. A complete description of this evaluation technique has been previously published. ${ }^{10}$

Additionally, a measure of emphysema distribution was obtained by using quantitative image analysis (QIA) of digitized spiral CT scans. Patients screened between October 1997 and July 2002 were imaged by using various single-slice spiral CT scanners. Patients were instructed to hold their breath at full inspiration (at or near-total lung capacity). A volumetric image data set was reconstructed, with slice thickness ranging between 5 and 10 $\mathrm{mm}$ (the majority of studies had a slice thickness of 7-8 $\mathrm{mm}$ ) and slice spacing set to half of the slice thickness. Image data were reconstructed by using the appropriate scanner equivalent of a normal reconstruction kernel. A software package developed by the University of Iowa (Pulmonary Analysis Software Suite) was used to identify the lungs, divide the lungs into the left and right lungs, and then divide each lung into the upper, middle, and lower thirds on the basis of the apex-to-base distance. The software also provided a set of metrics that characterized the distribution of Hounsfield unit (HU) levels for the voxels comprising each lung region, including the number of voxels with density of less than $-950 \mathrm{HU}$, a level generally accepted as corresponding to severe emphysema. This count was used with the total number of voxels comprising a region to obtain the proportion of emphysema for the region expressed as 
a percentage. The difference between the upper lung and the lower lung in the percentage of emphysema at the $-950 \mathrm{HU}$ threshold was used to categorize the disease. Those whose percentage of emphysema was greater in the upper than in the lower cuts were classified as upper lobe predominant emphysema and all others were non-upper-lobe-predominant emphysema.

A second distribution metric was calculated by the software on the basis of the number and size of holes in the lung, as demonstrated in the digitized CT scans. This was designated as the $\alpha$ measure and is based on the work of Mishima and colleagues. ${ }^{11}$ They hypothesized that if the initial onset of emphysema was a random process whereby small holes appeared randomly throughout a lung region, the log-log plot of the percentage of holes in that region versus hole size would prove to be linear. Then if the progression of the disease is based on the small holes destabilizing a region whereby small holes join to form large holes, the slope of the log-log plot of percentage holes ( $\mathrm{y}$-axis) versus hole size ( $\mathrm{x}$-axis) will decrease as larger holes increasingly dominate over small holes and provides a measure of emphysema severity. In our analysis a hole in the lung is defined as voxels of less than $-950 \mathrm{HU}$. The slope from the log-log relationship of hole size plotted against the number of "holes" determines the alpha value. The difference between the upper lung and the lower lung in alpha at the $-950 \mathrm{HU}$ threshold determines site of predominance. When alpha is less than 0 it is upper lobe predominant versus nonupper lobe predominant when it is 0 or higher.

Finally, a measurement of the distribution was obtained from nuclear imaging scans. The regional distribution was quantified, and the ratio of upper-lobe perfusion to lower-lobe perfusion was obtained.

All patients eligible for randomization were required to complete a 6- to 10-week course of formal outpatient pulmonary rehabilitation supervised by the clinical centers. After pulmonary rehabilitation, repeat physiologic testing and patient assessment was conducted before randomization to continued medical therapy with maintenance rehabilitation or LVRS, followed by continued medical treatment and maintenance rehabilitation.

Patients randomized to LVRS underwent a bilateral stapled wedge resection with the goal of resecting $20 \%$ to $35 \%$ of each lung. The resections were targeted by using the imaging modalities of both CT scans and nuclear images of the lung. Eight centers performed the operation by means of median sternotomy, 3 centers by means of video-assisted thoracic surgery, and 6 centers by means of median sternotomy or video-assisted thoracic surgery selected randomly.

\section{Definition of Outcome}

Because of the prolonged duration of hospitalization in many patients undergoing LVRS and the frequently observed discharge from the acute-care hospital to a chronic-care facility, neither 30-day mortality nor hospital discharge mortality were believed to be representative of the true risk of mortality. Thus the 90-day mortality from all causes (measured from the day of LVRS) was chosen as the best surrogate for overall operative mortality. Vital status was determined by using routine reports from the clinical centers, as well as from a review of the 2004 Death
Master File from the Social Security Administration. Major pulmonary morbidity was defined as the need within 30 days of the operation for tracheostomy, reintubation, or ventilator support for 3 or more days; pneumonia within 30 days of the operation; or ventilator dependency for more than 30 days after LVRS. Major cardiovascular morbidity was defined as intraoperative arrhythmia requiring pharmaceutical or electrophysiologic treatment or myocardial infarction, pulmonary embolus, or arrhythmia requiring treatment within 30 days after LVRS.

\section{Statistical Analysis}

Predictors for each of the 3 outcomes were investigated by using univariate and multivariate logistic regression. The relative odds (RO) obtained from the logistic regression expresses either the risk of the outcome for patients with the specified factor compared with the risk for patients without the factor (binary factor) or the incremental risk per each unit change in the factor (continuous factor). Candidate predictors were 23 clinical variables describing demographics (age, sex, and raceethnicity), physical condition (body mass index; oxygen use at rest, with exercise, and during sleep; prescription of oral steroids at the postrehabilitation, prerandomization visit; and serum creatinine level), pulmonary function measures (forced expiratory volume in 1 second $\left[\mathrm{FEV}_{1}\right]$ percent predicted, residual volume percent predicted, ratio of residual volume to total lung capacity ratio, the diffusing capacity for carbon monoxide [DLCO, $\mathrm{PaCO}_{2}$, and the ratio of expired volume to the volume of $\mathrm{CO}_{2}$ ), exercise capacity (6-minute walk distance and maximum exercise capacity by means of bicycle ergometry [categorized as low or high]), dyspnea (UCSD Shortness of Breath Questionnaire and St George's Respiratory Questionnaire scores) and quality of life (Quality of Well-Being Scale), and imaging measures (perfusion ratio and assessments by the study radiologists of heterogeneity, upper-lobe distribution, and hyperinflation), as well as by means of computerized analysis of CT scans performed at the imaging center.

The NETT was approved by the institutional review boards at each of the 17 clinical centers, and informed consent was obtained from all participants.

\section{Results}

Between January 1998 and July 2002, 3777 patients were considered for entry into the NETT, and 1218 progressed through screening evaluation, formal pulmonary rehabilitation, repeat physiologic and radiologic testing, and randomization to treatment. There were 610 patients assigned to medical therapy and 608 to surgical therapy. Of the 608 patients randomized to surgical therapy, 580 (95.4\%) eventually underwent LVRS either by using a median sternotomy approach (406 patients) or by means of video-assisted surgery (174 patients). Twenty-one patients randomized to LVRS declined surgical intervention, and 7 patients were deemed unsuitable for surgical intervention by the surgeon or anesthesiologist at some point after randomization. Sixty-nine of the 580 patients who underwent LVRS were in the subgroup identified by 
TABLE 1. Characteristics of patients at baseline* $(n=511)$

\begin{tabular}{|c|c|}
\hline Characteristic & Mean \pm SD or $n(\%)$ \\
\hline Age at surgical intervention, $y$ & $67.0 \pm 6.2$ \\
\hline \multicolumn{2}{|l|}{ Sex } \\
\hline Female & $219(42.9)$ \\
\hline Male & $292(57.1)$ \\
\hline \multicolumn{2}{|l|}{ Emphysema distribution on CT } \\
\hline Predominant upper lobe & $332(65.0)$ \\
\hline Predominant non-upper lobe & $179(35.0)$ \\
\hline Heterogeneous $(\%) \dagger$ & $295(57.7)$ \\
\hline Homogeneous $(\%) \dagger$ & $216(42.3)$ \\
\hline $\mathrm{FEV}_{1}$ after $\mathrm{BD}$ use, $\%$ predicted & $28.1 \pm 6.8$ \\
\hline TLC after BD use, $\%$ predicted & $127.3 \pm 15.1$ \\
\hline RV after BD use, $\%$ predicted & $214.4 \pm 45.6$ \\
\hline Dıco, \% predicted & $29.2 \pm 9.3$ \\
\hline $\mathrm{PaO}_{2}, \mathrm{~mm} \mathrm{Hg}$ & $65.2 \pm 10.6$ \\
\hline $\mathrm{PaCO}_{2}, \mathrm{~mm} \mathrm{Hg}$ & $42.8 \pm 5.6$ \\
\hline $\begin{array}{l}\text { Saint George's Respiratory Questionnaire } \\
\text { total score } \ddagger\end{array}$ & $52.2 \pm 12.8$ \\
\hline $\begin{array}{l}\text { UCSD Shortness of Breath Questionnaire } \\
\text { total score§ }\end{array}$ & $61.0 \pm 18.4$ \\
\hline $\begin{array}{l}\text { Quality of Well-Being Scale average } \\
\text { daily score } \|\end{array}$ & $0.58 \pm 0.12$ \\
\hline
\end{tabular}

$S D$, Standard deviation; $C T$, computed tomography; $F E V_{1}$, forced expiratory volume in 1 second; $B D$, bronchodilator; $T L C$, total lung capacity; $R V$, residual volume; $D\left\llcorner C O\right.$, diffusion capacity; $\mathrm{PaO}_{2}$, partial pressure of arterial oxygen; $\mathrm{PaCO}_{2}$, partial pressure of arterial carbon dioxide; UCSD, University of California at San Diego. *Baseline measurements are obtained after rehabilitation and before randomization, except for the diffusion capacity of carbon dioxide, which is obtained before rehabilitation and before randomization. †Emphysema distribution is based on scores assigned subjectively to each of 3 lung zones in each lung. $\ddagger$ The Saint George's Respiratory Questionnaire is a 51-item questionnaire completed by the patient with regard to respiratory symptoms, where the total score ranges from 0 to 100 , and lower scores indicate fewer respiratory symptoms. §The UCSD Shortness of Breath Questionnaire is a 24-item questionnaire completed by the patient with regard to shortness of breath, where the total score ranges from 0 to 120 , and lower scores indicate less shortness of breath. "The Quality of Well-Being Scale is a 77-item questionnaire completed by the patient with regard to quality of life. The average daily total score ranges from 0 to 1 , where higher scores indicate better quality of life.

the Data and Safety Monitoring Board as being at high risk of mortality after LVRS with little chance of functional benefit; enrollment of this patient subgroup in the NETT was terminated in May 2001. This high-risk patient subgroup has already been described in a previous publication, and they are excluded from this analysis. ${ }^{12}$ The remaining 511 non-high-risk patients who underwent LVRS are the subject of this report.

\section{Patient Characteristics}

Table 1 depicts baseline clinical characteristics. The majority of patients were men, and the average age at the time of the operation was 67 years. The distribution of
TABLE 2. Complications and mortality $(n=511)$

\begin{tabular}{lr}
\hline Intraoperative & \\
None & $91.0 \%$ \\
Hypotension & $0.4 \%$ \\
Arrhythmia & $1.2 \%$ \\
Arrhythmia requiring treatment & $1.0 \%$ \\
Hypoxemia & $2.2 \%$ \\
Cardiac arrest & $0.4 \%$ \\
Uncontrolled air leak & $1.0 \%$ \\
Postoperative (within 30 d of operation) & \\
None & $41.3 \%$ \\
Arrhythmia & $23.5 \%$ \\
Arrhythmia requiring treatment & $18.6 \%$ \\
Myocardial infarction & $1.0 \%$ \\
Failure of early extubation & $3.9 \%$ \\
Tracheostomy & $8.2 \%$ \\
Failure to wean & $5.1 \%$ \\
Reoperation for air leak & $3.3 \%$ \\
Pulmonary embolus & $0.8 \%$ \\
Readmission to ICU & $11.7 \%$ \\
Mediastinitis & $0.6 \%$ \\
Sternal debridement & $0.6 \%$ \\
Pneumonia & $18.2 \%$ \\
Urinary retention & $3.5 \%$ \\
Epidural catheter complications & $0.8 \%$ \\
Sepsis & $2.5 \%$ \\
Readmission within $72 \mathrm{~h}$ after discharge & $2.5 \%$ \\
Ventilated more than $2 \mathrm{~d}$ & $13.6 \%$ \\
At least 1 reintubation & $21.8 \%$ \\
Major pulmonary morbidity* & $29.8 \%$ \\
Major cardiac morbidity & $20.0 \%$ \\
Dead within $90 \mathrm{~d}$ of operation & $5.5 \%$ \\
\hline & \\
\hline
\end{tabular}

$I C U$, Intensive care unit. *Major pulmonary morbidity is defined as incidence of 1 or more of the following in the 30 days after lung volume reduction surgery: tracheostomy, failure to wean, pneumonia, at least 1 postoperative intubation, or ventilator use for 3 or more days. †Major cardiac morbidity is defined as incidence of 1 or more of the following: intraoperative or postoperative (in the 30 days after lung volume reduction surgery) arrhythmia requiring treatment or myocardial infarction or pulmonary embolus in the 30 days after lung volume reduction surgery.

emphysema was upper-lobe predominant in approximately two thirds of patients and judged as heterogeneous in $58 \%$ of patients. Mean $\mathrm{FEV}_{1}$ percent predicted was $28 \%$, and mean residual volume was $215 \%$ of predicted value. At baseline rest, patients were neither hypoxemic nor severely hypercapneic but did demonstrate a severe degree of dyspnea, as shown by the St George's Respiratory Questionnaire and the UCSD Shortness of Breath Questionnaire scores.

\section{Operative Morbidity}

Table 2 outlines the intraoperative and postoperative morbidity. More than $90 \%$ of patients had no intraoperative complications; however, more than $50 \%$ of patients had 
TABLE 3. Factors related to death 90 or fewer days after lung volume reduction surgery

\begin{tabular}{|c|c|c|c|c|c|}
\hline \multirow[b]{3}{*}{ Risk factor } & \multirow{3}{*}{$\begin{array}{l}\% \text { with risk factor } \\
\text { or mean }\end{array}$} & \multicolumn{4}{|c|}{$\begin{array}{l}\text { Logistic regression relative odds of death } \\
\text { within } 90 \text { days* }\end{array}$} \\
\hline & & \multicolumn{2}{|c|}{ Unadjusted } & \multicolumn{2}{|c|}{$\begin{array}{l}\text { Final model after } \\
\text { backward selection }\end{array}$} \\
\hline & & RO & $P$ valuet & RO & $P$ valuef \\
\hline No. of patients & 511 & & & $425 \S$ & \\
\hline \multicolumn{6}{|l|}{ Demographics } \\
\hline Age at operation, y (per y of age) & 67.0 & 1.07 & .06 & - & - \\
\hline Minority (yes vs no) & $4.7 \%$ & 0.74 & .77 & - & - \\
\hline Male sex (yes vs no) & $57.1 \%$ & 1.62 & .24 & - & - \\
\hline \multicolumn{6}{|l|}{ Treatment and physical condition } \\
\hline Body mass index, $\mathrm{kg} / \mathrm{m}^{2}$ (per unit change) & 24.7 & 0.94 & .25 & - & - \\
\hline Using oxygen constantly (yes vs no) & $49.1 \%$ & 1.41 & .38 & - & - \\
\hline Prescribed oral steroids at baseline (yes vs no) & $31.9 \%$ & 0.85 & .70 & - & - \\
\hline Abnormal creatinine level at baseline (yes vs no) & $10.6 \%$ & 1.02 & .98 & - & - \\
\hline \multicolumn{6}{|l|}{ Radiologic measures } \\
\hline Nonheterogeneous (radiologist evaluation; yes vs no) & $42.3 \%$ & 1.20 & .65 & - & - \\
\hline Non-upper lobe (radiologist evaluation; yes vs no) & $35.0 \%$ & 3.06 & .005 & 2.99 & .009 \\
\hline Hyperinflation on chest radiograph (any vs none) & $96.6 \%$ & 0.94 & .95 & - & - \\
\hline Perfusion ratio (per unit change) & 0.30 & 2.31 & .23 & - & - \\
\hline Non-upper lobe, QIA $\alpha$ measure ( $\mathrm{n}=458$; yes vs no) & $47.4 \%$ & 2.63 & .03 & - & - \\
\hline $\begin{array}{l}\text { Non-upper lobe, OIA \% emphysema measure ( } n=458 \text {; } \\
\text { yes vs no) }\end{array}$ & $22.1 \%$ & 1.32 & .54 & - & - \\
\hline \multicolumn{6}{|l|}{ Pulmonary function measures } \\
\hline $\mathrm{FEV}_{1}$ percent predicted (per unit change) & 28.1 & 1.00 & .90 & - & - \\
\hline RV percent predicted (per unit change) & 214.4 & 1.00 & .74 & - & - \\
\hline RV/TLC (per unit change) & 0.64 & 0.04 & .19 & - & - \\
\hline Dıco percent predicted (per unit change) & 29.2 & 0.97 & .21 & - & - \\
\hline $\mathrm{PacO}_{2}$ (per mm Hg) & 42.8 & 0.97 & .46 & - & - \\
\hline \multicolumn{6}{|l|}{ Exercise measures } \\
\hline Low exercise (yes vs no) & $40.9 \%$ & 0.93 & .86 & - & - \\
\hline $\mathrm{Ve} / \mathrm{VCO}_{2}$ at max work (per unit change) & 0.37 & 6.79 & .33 & - & - \\
\hline Six-min walk distance (per ft) & 1246 & 1.00 & .53 & - & - \\
\hline \multicolumn{6}{|l|}{ QOL measures } \\
\hline UCSD SOB total score (per unit change) & 61.0 & 1.00 & .79 & - & - \\
\hline QWB average daily score (per unit change) & 0.58 & 2.71 & .55 & - & - \\
\hline
\end{tabular}

$R O$, Relative odds; $Q I A$, quantitative image analysis; $F E V_{1}$, forced expiratory volume in 1 second; $R V$, residual volume; $T L C$, total lung capacity; $D L C O$, diffusion capacity; $\mathrm{PaCO}_{2}$, partial pressure of arterial carbon dioxide; $\mathrm{Ve} / \mathrm{VCO}_{2}$, ratio of expired volume to the volume of carbon dioxide; $Q 0 \mathrm{~L}$, quality of life; UCSD SOB, University of California at San Diego Shortness of Breath Questionnaire; QWB, Quality of Well-Being Scale. *Relative odds is defined as the ratio of the odds for those with versus the odds for those without the factor (yes vs no) or incremental odds for each specified change in the factor (continuous). $†$ Wald $\chi^{2}$ test for logistic regression with response variable of death within 90 days of lung volume reduction surgery and regressor of risk factor. $\ddagger P$ value for stepwise logistic regression (forward selection) with response variable of death within 90 days of lung volume reduction surgery (yes vs no) and candidate regressors of all factors listed in the table. $\S n=511$ because of missing data and ability to estimate.

significant postoperative complications. As noted in Table 2, the most frequent complication was the need for reintubation (22\%), followed by postoperative arrhythmia requiring therapy (19\%), pneumonia (18\%), mechanical ventilation for 3 or more days (14\%), and the need for a tracheostomy $(8 \%)$. Of note, almost $12 \%$ of patients required readmission to the intensive care unit at some time during the initial hospitalization. The incidence of major pulmonary morbidity was almost $30 \%$, and the incidence of major cardiac morbidity was $20 \%$.

\section{Operative (90-day) Mortality}

The 90-day mortality after LVRS was 5.5\% (28 patients, Table 2) among the 511 non-high-risk patients. The stated cause of death was respiratory (pneumonia, acute respiratory distress syndrome, aspiration, and progressive respiratory failure) in $12(43 \%)$ patients, cardiovascular (infarction, arrhythmia, and pulmonary embolism) in 5 (18\%) patients, multiorgan failure in $2(7 \%)$ patients, cerebrovascular accident and sepsis in 1 (4\%) patient each, and unclassified in 7 (25\%) patients. As noted in Table 3, univar- 
TABLE 4. Factors related to major pulmonary morbidity in the $\mathbf{3 0}$ days after lung volume reduction surgery*

\begin{tabular}{|c|c|c|c|c|c|}
\hline \multirow[b]{3}{*}{ Risk factor } & \multirow{3}{*}{$\begin{array}{c}\% \text { with risk factor or } \\
\text { mean }\end{array}$} & \multicolumn{4}{|c|}{$\begin{array}{l}\text { Logistic regression relative odds of } \\
\text { pulmonary morbidity in } 30 \mathrm{dt}\end{array}$} \\
\hline & & \multicolumn{2}{|c|}{ Unadjusted } & \multicolumn{2}{|c|}{$\begin{array}{c}\text { Final model after } \\
\text { backward selection }\end{array}$} \\
\hline & & RO & $P$ valuef & RO & $P$ value§ \\
\hline No. of patients & 511 & & & $440 \|$ & \\
\hline \multicolumn{6}{|l|}{ Demographics } \\
\hline Age at operation, y (per y of age) & 67.0 & 1.03 & .08 & 1.05 & .02 \\
\hline Minority (yes vs no) & $4.7 \%$ & 0.78 & .60 & - & - \\
\hline Male sex (yes vs no) & $57.1 \%$ & 1.22 & .32 & - & - \\
\hline \multicolumn{6}{|l|}{ Treatment and physical condition } \\
\hline Body mass index, $\mathrm{kg} / \mathrm{m}^{2}$ (per unit change) & 24.7 & 0.97 & .32 & - & - \\
\hline Using oxygen constantly (yes vs no) & 49.1 & 1.48 & .05 & - & - \\
\hline Prescribed oral steroids at baseline (yes vs no) & $31.9 \%$ & 0.94 & .76 & - & - \\
\hline Abnormal creatinine level at baseline (yes vs no) & $10.6 \%$ & 1.21 & .54 & - & - \\
\hline \multicolumn{6}{|l|}{ Radiologic measures } \\
\hline Nonheterogeneous (radiologist evaluation; yes vs no) & $42.3 \%$ & 0.95 & .81 & - & - \\
\hline Non-upper lobe (radiologist evaluation; yes vs no) & $35.0 \%$ & 1.12 & .58 & - & - \\
\hline Hyperinflation on chest radiograph (any vs none) & $96.6 \%$ & 1.02 & .97 & - & - \\
\hline Perfusion ratio (per unit change) & 0.30 & 1.05 & .91 & - & - \\
\hline Non-upper lobe, QIA $\alpha$ measure ( $n=458$; yes vs no) & $47.4 \%$ & 1.09 & .68 & - & - \\
\hline Non-upper lobe, QIA \% emphysema measure ( $n=458$; yes vs no) & $22.1 \%$ & 0.92 & .74 & - & - \\
\hline \multicolumn{6}{|l|}{ Pulmonary function measures } \\
\hline $\mathrm{FEV}_{1}$ percent predicted (per unit change) & 28.1 & 0.97 & .03 & 0.97 & .05 \\
\hline RV percent predicted (per unit change) & 214.4 & 1.00 & .55 & - & - \\
\hline RV/TLC (per unit change) & 0.64 & 2.49 & .45 & - & - \\
\hline Dıco percent predicted (per unit change) & 29.2 & 0.97 & .003 & 0.97 & .01 \\
\hline $\mathrm{PaCO}_{2}($ per $\mathrm{mm} \mathrm{Hg})$ & 42.8 & 1.00 & .79 & - & - \\
\hline \multicolumn{6}{|l|}{ Exercise measures } \\
\hline Low exercise (yes vs no) & $40.9 \%$ & 1.57 & .02 & - & - \\
\hline $\mathrm{Ve} / \mathrm{VCO}_{2}$ (per unit change) & 0.37 & 2.40 & 0.42 & - & - \\
\hline Six-min walk distance (per ft) & 1246 & 1.00 & .10 & - & - \\
\hline \multicolumn{6}{|l|}{ QOL measures } \\
\hline UCSD SOB total score (per unit change) & 61.0 & 1.01 & .22 & - & - \\
\hline QWB average daily score (per unit change) & 0.58 & 0.36 & .23 & - & - \\
\hline
\end{tabular}

$R O$, Relative odds; $Q I A$, quantitative image analysis; $F E V_{1}$, forced expiratory volume in 1 second; $R V$, residual volume; $T L C$, total lung capacity; $D L C O$, diffusion capacity; $\mathrm{PaCO}_{2}$, partial pressure of arterial carbon dioxide; $\mathrm{Ve} / \mathrm{VCO}_{2}$, ratio of expired volume to the volume of carbon dioxide; $Q 0 \mathrm{~L}$, quality of life; UCSD SOB, University of California at San Diego Shortness of Breath Questionnaire; QWB, Quality of Well-Being Scale. *Major pulmonary morbidity is defined as incidence of 1 or more of the following in the 30 days after lung volume reduction surgery: tracheostomy, failure to wean, pneumonia, at least 1 postoperative intubation, or ventilator use for 3 or more days. †Relative odds is defined as the ratio of the odds for those with versus the odds for those without the factor (yes vs no) or incremental odds for each specified change in the factor (continuous). $\neq$ Wald $\chi^{2}$ test for logistic regression with response variable of major pulmonary morbidity in the 30 days after lung volume reduction surgery (yes vs no) and regressor of risk factor. $\S P$ value for stepwise logistic regression (forward selection) with response variable of major pulmonary morbidity in the 30 days after lung volume reduction surgery and candidate regressors of all factors listed in the table. $\| n=511$ because of missing data.

iate analysis suggested several factors potentially predictive for operative mortality, including age at the time of the operation $(P=.06)$, non-upper-lobe-predominant emphysema determined by the radiologist $(P=.005)$, and nonupper-lobe emphysema determined by using the $\alpha$ measure with quantitative CT image analysis $(P=.03)$. The logistic regression model with backward selection determined that a single factor, non-upper-lobe-predominant emphysema determined by the radiologist, was predictive of 90 -day mortality (RO, 2.99; $P=.009)$.

\section{Major Pulmonary Morbidity}

The univariate analysis suggested several factors potentially predictive for major pulmonary morbidity in the first 30 days after LVRS (Table 4). These included age at the time of the operation $(P=.08)$, continuous oxygen use $(P=$ $.05), \mathrm{FEV}_{1}$ percent predicted $(P=.03)$, DLco percent predicted $(P=.003)$, and low exercise capacity, as measured by means of symptom-limited maximum cycle ergometry $(P=.02)$. However, the logistic regression model determined that only 3 of these factors were in- 
TABLE 5. Factors related to major cardiac morbidity in the $\mathbf{3 0}$ days after lung volume reduction surgery*

\begin{tabular}{|c|c|c|c|c|c|}
\hline \multirow[b]{3}{*}{ Risk factor } & \multirow{3}{*}{$\begin{array}{l}\% \text { with risk factor } \\
\text { or mean }\end{array}$} & \multicolumn{4}{|c|}{$\begin{array}{c}\text { Logistic regression relative odds of cardiac } \\
\text { morbidity in } 30 \text { dayst }\end{array}$} \\
\hline & & \multicolumn{2}{|c|}{ Unadjusted } & \multicolumn{2}{|c|}{$\begin{array}{c}\text { Final model after } \\
\text { backward selection }\end{array}$} \\
\hline & & RO & $P$ value $\neq$ & RO & $P$ value§ \\
\hline No. of patients & 511 & & & $440 \|$ & \\
\hline \multicolumn{6}{|l|}{ Demographics } \\
\hline Age at operation, y (per y of age) & 67.0 & 1.07 & .001 & 1.07 & .004 \\
\hline Minority (yes vs no) & $4.7 \%$ & 0.56 & .36 & - & - \\
\hline Male sex (yes vs no) & $57.1 \%$ & 1.84 & .01 & - & - \\
\hline \multicolumn{6}{|l|}{ Treatment and physical condition } \\
\hline Body mass index, $\mathrm{kg} / \mathrm{m}^{2}$ (per unit change) & 24.7 & 0.99 & .82 & - & - \\
\hline Using oxygen constantly (yes vs no) & 49.1 & 1.27 & .28 & - & - \\
\hline Prescribed oral steroids at baseline (yes vs no) & $31.9 \%$ & 1.35 & .20 & 1.72 & .04 \\
\hline Abnormal creatinine level at baseline (yes vs no) & $10.6 \%$ & 1.64 & .13 & - & - \\
\hline \multicolumn{6}{|l|}{ Radiologic measures } \\
\hline Nonheterogeneous (radiologist evaluation; yes vs no) & $42.3 \%$ & 1.21 & .39 & - & - \\
\hline Non-upper lobe (radiologist evaluation; yes vs no) & $35.0 \%$ & 1.32 & .22 & - & - \\
\hline Hyperinflation on chest radiograph (any vs none) & $96.6 \%$ & 0.44 & .12 & - & - \\
\hline Perfusion ratio (per unit change) & 0.30 & 2.21 & .09 & - & - \\
\hline Non-upper lobe, QIA $\alpha$ measure ( $\mathrm{n}=458$; yes vs no) & $47.4 \%$ & 2.65 & $<.001$ & 2.67 & $<.001$ \\
\hline Non-upper lobe, QIA \% emphysema measure ( $n=458$; yes vs no) & $22.1 \%$ & 1.53 & .11 & - & - \\
\hline \multicolumn{6}{|l|}{ Pulmonary function measures } \\
\hline $\mathrm{FEV}_{1}$ percent predicted (per unit change) & 28.1 & 0.99 & .53 & - & - \\
\hline RV percent predicted (per unit change) & 214.4 & 1.00 & .84 & - & - \\
\hline $\mathrm{RV} / \mathrm{TLC}$ & 0.64 & 0.73 & .82 & - & - \\
\hline Dıco percent predicted (per unit change) & 29.2 & 1.00 & .84 & - & - \\
\hline $\mathrm{PaCO}_{2}$ (per mm Hg) & 42.8 & 1.03 & .09 & - & - \\
\hline \multicolumn{6}{|l|}{ Exercise measures } \\
\hline Low exercise (yes vs no) & $40.9 \%$ & 1.59 & .04 & - & - \\
\hline $\mathrm{Ve} / \mathrm{VCO}_{2}$ (per unit change) & 0.37 & 1.51 & .74 & - & - \\
\hline Six-min walk distance (per ft) & 1246 & 1.00 & .12 & - & - \\
\hline \multicolumn{6}{|l|}{ QOL measures } \\
\hline UCSD SOB total score (per unit change) & 61.0 & 0.99 & .22 & - & - \\
\hline QWB average daily score (per unit change) & 0.58 & 1.19 & .86 & - & - \\
\hline
\end{tabular}

$R O$, Relative odds; $Q I A$, quantitative image analysis; $F E V_{1}$, forced expiratory volume in 1 second; $R V$, residual volume; $T L C$, total lung capacity; $D L C O$, diffusion capacity; $P_{a C O}$, partial pressure of arterial carbon dioxide; $\mathrm{Ve} / \mathrm{VCO}_{2}$, ratio of expired volume to the volume of carbon dioxide; $Q O L$, quality of life; UCSD SOB, UCSD Shortness of Breath Questionnaire; OWB, Quality of Well-Being Scale. *Major cardiac morbidity is defined as incidence of 1 or more of the following: intraoperative or postoperative (in the 30 days after lung volume reduction surgery) arrhythmia requiring treatment or myocardial infarction or pulmonary embolus in the 30 days after lung volume reduction surgery. $†$ Relative odds is defined as the ratio of the odds for those with versus the odds for those without the factor (yes vs no) or incremental odds for each specified change in the factor (continuous). $\ddagger$ Wald $\chi^{2}$ test for logistic regression with response variable of major cardiac morbidity in the 30 days after lung volume reduction surgery (yes vs no) and regressor of risk factor. $\S P$ value for stepwise logistic regression (forward selection) with response variable of major cardiac morbidity in the 30 days after lung volume reduction surgery and candidate regressors of all factors listed in the table. $\| \mathrm{n}=511$ because of missing data.

deed independent predictors for pulmonary morbidity. These included age (RO, 1.05; $P=.02$ ), $\mathrm{FEV}_{1}$ percent predicted (RO, 0.97; $P=.05)$, and DLCo percent predicted (RO, 0.97; $P=.01$ ).

\section{Major Cardiac Morbidity}

Table 5 shows the analysis for predictors of major cardiac morbidity. The univariate analysis suggests that as many as 6 factors might be predictive for major cardiac morbidity. These include age at the time of the operation $(P=.001)$, male sex $(P=.01)$, perfusion ratio $(P=.09)$, non-upperlobe-predominant emphysema determined from the $\alpha$ measure from the quantitative CT image analysis $(P<.001)$, $\mathrm{PaCO}_{2}(P=.09)$, and low exercise capacity $(P=.04)$. However, the multivariate logistic regression determined only 3 factors proved to be independent predictors, and these included age at the time of the operation (RO, 1.07; $P=.004)$, oral steroid use at the time of the operation (RO, $1.72 ; P=.04)$, and non-upper-lobe-predominant emphy- 


\section{TABLE 6. Predictors of mortality in prior publications}

\begin{tabular}{|c|c|}
\hline$\overline{\mathrm{Age}}$ & $\begin{array}{l}\text { Naunheim and coworkers } \\
\text { Glaspole and coworkers }\end{array}$ \\
\hline Male sex & $\begin{array}{l}\text { Naunheim and coworkers } \\
\text { Ciccone and coworkers }\end{array}$ \\
\hline Exercise tolerance & $\begin{array}{l}\text { Szekely and coworkers }{ }^{4} \\
\text { Naunheim and coworkers } \\
\text { Geddes and coworkers } \\
{ }^{7} \\
\text { Ciccone and coworkers }{ }^{13}\end{array}$ \\
\hline $\mathrm{PaCO}_{2}$ & $\begin{array}{l}\text { Szekely and coworkers }{ }^{4} \\
0^{\prime} \text { Brien and coworkers }{ }^{14} \\
\text { Keenan and coworkers }{ }^{5}\end{array}$ \\
\hline $\mathrm{FEV}_{1}$ & $\begin{array}{l}\text { NETT }^{10} \\
\text { Ciccone and coworkers }\end{array}$ \\
\hline DLco & $\begin{array}{l}\text { Geddes and coworkers }{ }^{7} \\
\text { Keenan and coworkers }^{5} \\
\text { NETT }^{10}\end{array}$ \\
\hline Imaging studies & $\begin{array}{l}\text { Slone and coworkers }{ }^{16} \\
\text { Wisser and coworkers }^{15} \\
\text { NETT }^{10} \\
\text { Weder and coworkers }\end{array}$ \\
\hline
\end{tabular}

$\mathrm{PaCO}_{2}$, Partial pressure of arterial carbon dioxide; $\mathrm{FEV}_{1}$, forced expiratory volume in 1 second; NETT, National Emphysema Treatment Trial; Dıco, diffusion capacity.

sema determined by the $\alpha$ measure by using quantitative image analysis $(\mathrm{RO}, 2.67 ; P<.001)$.

\section{Discussion}

Reported predictors of short-term mortality, operative mortality, or both after LVRS have included many factors describing patient demographic profile, spirometry, lung volume, gas exchange, exercise tolerance, and imaging studies (Table 6). ${ }^{4-8,10,13-17}$ Unfortunately, the predictive risk factors vary widely from article to article, and their validity is questionable. In several reports age is described as a strong predictor of morbidity 6,8 yet is reported to be insignificant in others. ${ }^{4,5,13}$ Similarly, $\mathrm{PaCO}_{2}$ was noted as a significant risk factor by some investigators ${ }^{4,14,16}$ but not by others. ${ }^{6,13,15}$ Likely some of this uncertainty is due to the very nature of the studies cited. They were, in general, single-institution, nonrandomized, uncontrolled trials that involved small numbers of patients with variable measures and time points for evaluation, as well as a lack of consistency in the manner in which testing was conducted. Selection criteria varied from institution to institution, and the operative techniques varied widely as well.

The lack of consistency between these reports made risk assessment quite problematic for physicians counseling patients regarding the risks and benefits of LVRS. However, many of the above shortcomings were addressed with the institution of the NETT, a prospective, multi-institutional, randomized controlled trial that eventually enrolled more than 1200 patients. One of the major secondary end points in the NETT was to provide clinical insight to allow for optimal patient selection, both with regard to risk and outcome. The NETT protocol was carefully designed to comprehensively characterize patients' preoperative pulmonary, cardiac, and functional status to diminish the effect of underlying significant diseases that would adversely affect patient outcome. Therefore the complications that we report in this study are ones that occurred in the setting of patients who had no overt signs of existing cardiopulmonary disease before LVRS other than their emphysema.

The first clinical publication of the NETT fulfilled this goal partially when it identified a subgroup of patients at exceedingly high risk for operative mortality and poor outcome measured at 6 months. ${ }^{11}$ Those patients with an $\mathrm{FEV}_{1}$ of less than $20 \%$ of predicted value and either a DLCo of less than $20 \%$ of predicted value or homogeneous distribution of emphysema as assessed by the radiologist were found to have a high 30-day mortality (16\%) without substantially improved functional outcome in survivors compared with that seen in the medically treated control group at 6 months after randomization to treatment. Once this high-risk subgroup was identified, such patients were excluded from further entry into the trial; however, accrual of non-highrisk patients continued. A subsequent NETT publication has identified predictors of outcome and survival after an average of 29 months of follow-up; however, an analysis regarding early surgical mortality and morbidity has been lacking up to the present time. ${ }^{1}$

Significant cardiac morbidity has been rarely reported with LVRS, with the exception of the development of arrhythmias, including atrial fibrillation, supraventricular tachycardia, and some ventricular arrhythmias. The only independent predictors for cardiac morbidity were increasing age, oral steroid use, and non-upper-lobe-predominant emphysema identified by the $\alpha$ measure on QIA. It is doubtful whether preoperative identification of these factors would likely be of great benefit in avoiding cardiac morbidity. The QIA model is not widely available, and the effect of increasing age, although significant, is so small it is unlikely to be of great clinical value. Perhaps clinically, the most practical suggestion would be to consider prophylactic pharmacologic prevention, as is currently undertaken in many cardiac surgery practices. Indeed, the incidence of these arrhythmias approaches that found after routine coronary artery bypass surgery, and prophylaxis might prove to be the best strategy. However, because this strategy was not studied, its value is purely speculative.

Pulmonary morbidity is perhaps the most daunting aspect of perioperative care for patients undergoing LVRS. Approximately $5 \%$ of patients fall into the failure to wean category, $18 \%$ had pneumonia, and $8 \%$ eventually proceed to tracheostomy, whereas more than $7 \%$ of patients will spend more than 2 weeks on the ventilator. Once again, 
looking to the independent predictors for help in avoiding significant pulmonary morbidity will likely prove futile. Although age, $\mathrm{FEV}_{1}$ percent predicted, and DLCo are all statistically predictive of increased pulmonary morbidity, the changes in the RO ratio are not great, and it is highly unlikely any specific threshold could be identified that would represent a valid cutoff for patients or physicians. Perhaps patients with 2 or more risk factors (age $>70$ years and either $\mathrm{FEV}_{1}$ or DLCO approaching $20 \%$ of predicted value) should be seen as approaching the previously published high-risk cohort and could be reasonably counseled against LVRS.

Perhaps the only area in which this risk analysis model is likely to be helpful clinically is in the arena of operative mortality. non-upper-lobe-predominant emphysema determined by the radiologist had an RO ratio of $2.99(P=.009)$, suggesting that even in this non-high-risk group, patients with non-upper-lobe-predominant emphysema carry a significantly increased risk of dying within the first 90 days after LVRS. This factor has already been shown to be predictive of both poor physiologic outcome and worse operative mortality in a cohort of patients with preserved exercise capacity. ${ }^{1,12}$ The current findings emphasize the point that the distribution of emphysema identified on the chest CT might be useful in guiding the physician in counseling the patient regarding the advisability of this procedure. A practitioner considering LVRS must think long and hard before suggesting this surgical intervention for patients who have been demonstrated as having non-upper-lobepredominant emphysema, even if all other factors appear encouraging. Although it is impossible to predict results in any individual patient, the combination of relatively increased operative mortality coupled with the inferior outcomes already described makes the decision for surgical intervention in this particular patient subgroup highly suspect.

\section{References}

1. Fishman A, Martinez F, Naunheim K, Piantadosi A, Wise R, Ries A, et al. A randomized trial comparing LVRS with medical therapy for severe emphysema. N Engl J Med. 2003;348:2059-73.

2. Cooper JD, Patterson GA, Sundaresan RS, Trulock EP, Yusen RD, Pohl MS, et al. Results of 150 consecutive bilateral lung volume reduction procedures in patients with severe emphysema. $J$ Thorac Cardiovasc Surg. 1996;112:1319-30.

3. Department of Health and Human Services. LVRS and Medicare Coverage Policy: implications of recently published evidence. Health Care Financing Administration report to Congress. Washington, DC: Department of Health and Human Services; 1998.

4. Szekely LA, Oelberg DA, Wright C, Johnson DC, Wain J, TrotmanDickenson B, et al. Preoperative predictors of operative morbidity and mortality in COPD patients undergoing bilateral LVRS. Chest. 1997; 111:550-8.

5. Keenan RJ, Landreneau RJ, Sciurba FC, Ferson PF, Holbert JM, Brown ML, et al. Unilateral thoracoscopic surgical approach for diffuse emphysema. J Thorac Cardiovasc Surg. 1996;111:308-16.

6. Naunheim KS, Hazelrigg SR, Kaiser LR, Keenan RJ, Bavaria JE, Landreneau RJ, et al. Risk analysis for thoracoscopic lung volume reduction: a multi-institutional experience. Eur J Cardiothorac Surg. 2000;17:673-9.

7. Geddes D, Davies M, Koyama H, Hansell D, Pastorino U, Pepper J, et al. Effect of LVRS in patients with severe emphysema. N Engl J Med. 2000;343:239-45.

8. Glaspole IN, Gabbay E, Smith JA, Rabinov M, Snell GI. Predictors of peri-operative morbidity and mortality in LVRS. Ann Thorac Surg. 2000;69:1711-6.

9. McKenna RJ, Brenner M, Fischel RJ, Singh N, Yoong B, Gelb AF et al. Patient selection criteria for lung volume reduction surgery. J Thorac Cardiovasc Surg. 1997;114:957-67.

10. National Emphysema Treatment Trial Research Group. Rationale and design of the National Emphysema Treatment Trial: a prospective randomized trial of lung volume reduction surgery. Chest. 1999;116: 1750-61.

11. Mishima M, Hirai $T$, Itoh $H$, Nakano $Y$, Sakai H, Muro S, et al. Complexity of terminal airspace geometry assessed by lung computed tomography in normal subjects and patients with chronic obstructive pulmonary disease. Proc Natl Acad Sci U S A. 1999;96:8829-34.

12. National Emphysema Treatment Trial Research Group. Patients at high risk of death after LVRS. N Engl J Med. 2001;345:1075-83.

13. Ciccone AM, Myers BF, Guthrie TJ, Davis GE, Yusen RD, Lefrak SS, et al. Long-term outcome of bilateral lung volume reduction in 250 consecutive patients with emphysema. J Thorac Cardiovasc Surg. 2003;125:513-25.

14. O'Brien GM, Furukawa S, Kuzma AM, Cordova F, Criner GJ. Improvements in lung function, exercise and quality of life in hypercapneic COPD patients after lung volume reduction surgery. Chest. 1999; 115:75-84.

15. Wisser W, Klepetko W, Kontrus M, Bankier A, Senbaklavaci Ő, Kaider A, et al. Morphologic grading of the emphysematous lung and its relation to improvement after LVRS. Ann Thorac Surg. 1998;65: 793-9.

16. Slone RM, Pilgram TK, Gierada DS, Sagel SS, Glazer HS, Yusen RD, et al. LVRS: a comparison of preoperative radiologic features and clinical outcome. Radiology. 1997;204:613-5.

17. Weder W, Thurnheer R, Stammberger U, Bürge M, Russi EW, Bloch KE. Radiologic emphysema morphology is associated with outcome after surgical lung volume reduction. Ann Thorac Surg. 1997;64: 313-20.

\section{Appendix}

The members of the National Emphysema Treatment Trial Research Group were as follows: Office of the Chair of the Steering Committee, University of Pennsylvania, Philadelphia, Pa-A. P. Fishman, B. A. Bozzarello, A. Al-Amin. Clinical Centers: Baylor College of Medicine, Houston, Tex-M. Katz, C. Wheeler, E. Baker, P. Barnard, J. Carter, S. Chatziioannou, K. Conejo-Gonzales, J. Haddad, D. Hicks, N. Kleiman, M. Milburn-Barnes, C. Nguyen, M. Reardon, J. Reeves-Viets, S. Sax, A. Sharafkhaneh, C. Young, R. Espada, R. Butanda, K. Dubose, M. Ellisor, P. Fox, K. Hale, E. Hood, A. Jahn, S. Jhingran, K. King, C. Miller, I. Nizami, T. Officer, J. Ricketts, J. Rodarte, R. Teague, K. Williams; Brigham and Women's Hospital, Boston, Mass-J. Reilly, D. Sugarbaker, C. Fanning, S. Body, S. Duffy, V. Formanek, A. Fuhlbrigge, P. Hartigan, S. Hooper, A. Hunsaker, F. Jacobson, M. Moy, S. Peterson, R. Russell, D. Saunders, S. Swanson; CedarsSinai Medical Center, Los Angeles, Calif-R. McKenna, Z. Mohsenifar, C. Geaga, M. Biring, S. Clark, R. Frantz, P. Julien, M. Lewis, J. Minkoff-Rau, V. Yegyan, M. Joyner; Cleveland Clinic Foundation, Cleveland, Ohio-M. DeCamp, J. Stoller, Y. Meli, J. Apostolakis, D. Atwell, J. Chapman, P. DeVilliers, R. Dweik, E. Kraenzler, R. Lann, N. Kurokawa, S. Marlow, K. McCarthy, P. McCreight, A. Mehta, M. Meziane, O. Minai, P. O'Donovan, M. Steiger, K. White, J. Maurer, C. Hearn, S. Lubell, R. Schilz, T. 
Durr; Columbia University, New York, and Long Island Jewish Medical Center, New Hyde Park, NY-M. Ginsburg, B. Thomashow, P. Jellen, J. Austin, M. Bartels, Y. Berkman, P. Berkoski, F. Brogan, A. Chong, G. DeMercado, A. DiMango, B. Kachulis, A. Khan, B. Mets, M. O'Shea, G. Pearson, J. Pfeffer, L. Rossoff, S. Scharf, M. Shiau, P. Simonelli, K. Stavrolakes, D. Tsang, D. Vilotijevic, C. Yip, M. Mantinaos, M. McKeon; Duke University Medical Center, Durham, NC-N. MacIntyre, R. D. Davis, J. Howe, R. E. Coleman, R. Crouch, D. Greene, K. Grichnik, D. Harpole, A. Krichman, B. Lawlor, H. McAdams, J. Plankeel, S. Rinaldo-Gallo, J. Smith, M. Stafford-Smith, V. Tapson, M. Steele, J. Norten; Mayo Foundation, Rochester, Minn-J. Utz, C. Deschamps, K. Mieras, M. Abel, M. Allen, D. Andrist, G. Aughenbaugh, S. Bendel, E. Edell, M. Edgar, B. Edwards, B. Elliot, J. Garrett, D. Gillespie, J. Gurney, B. Hammel, K. Hanson, L. Hanson, G. Harms, J. Hart, T. Hartman, R. Hyatt, E. Jensen, N. Jenson, S. Kalra, P. Karsell, D. Midthun, C. Mottram, S. Swensen, A.-M. Sykes, K. Taylor, N. Torres, R. Hubmayr, D. Miller, S. Bartling, K. Bradt; National Jewish Medical and Research Center, Denver, Colo-B. Make, M. Pomerantz, M. Gilmartin, J. Canterbury, M. Carlos, P. Dibbern, E. Fernandez, L. Geyman, C. Hudson, D. Lynch, J. Newell, R. Quaife, J. Propst, C. Raymond, J. WhalenPrice, K. Winner, M. Zamora, R. Cherniack; Ohio State University, Columbus, Ohio-P. Diaz, P. Ross, T. Bees, H. Awad, J. Drake, C. Emery, M. Gerhardt, M. Kelsey, M. King, D. Rittinger, M. Rittinger; Saint Louis University, St Louis, Mo-K. Naunheim, F. Alvarez, J. Osterloh, S. Borosh, W. Chamberlain, S. Frese, A. Hibbit, M. E. Kleinhenz, G. Ruppel, C. Stolar, J. Willey, C. Keller; Temple University, Philadelphia, $\mathrm{Pa}-\mathrm{G}$. Criner, S. Furukawa, A. M. Kuzma, R. Barnette, N. Brister, K. Carney, W. Chatila, F. Cordova, G. D'Alonzo, M. Keresztury, K. Kirsch, C. Kwak, K. Lautensack, M. Lorenzon, U. Martin, P. Rising, S. Schartel, J. Travaline, G. Vance, P. Boiselle, G. O'Brien; University of California, San Diego, San Diego, Calif-A. Ries, R. Kaplan, C. Ramirez, D. Frankville, P. Friedman, J. Harrell, J. Johnson, D. Kapelanski, D. Kupferberg, C. Larsen, T. Limberg, M. Magliocca, F. J. Papatheofanis, D. Sassi-Dambron, M. Weeks; University of Maryland at Baltimore, Baltimore, and Johns Hopkins Hospital, Baltimore, Md-M. Krasna, H. Fessler, I. Moskowitz, T. Gilbert, J. Orens, S. Scharf, D. Shade, S. Siegelman, K. Silver, C. Weir, C. White; University of Michigan, Ann Arbor, Mich-F. Martinez, M. Iannettoni, C. Meldrum, W. Bria, K. Campbell, P. Christensen, K. Flaherty, S. Gay, P. Gill, P. Kazanjian, E. Kazerooni, V. Knieper, T. Ojo, L. Poole, L. Quint, P. Rysso, T. Sisson, M. True, B. Woodcock, L. Zaremba; University of Pennsylvania, Philadelphia, Pa-L. Kaiser, J. Hansen-Flaschen, M. L. Geraghty, A. Alavi, T. Alcorn, J. Aronchick, S. Aukberg, B. Benedict, S. Craemer, R. Daniele, J. Edelman, W. Gefter, L. Kotler-Klein, R. Kotloff, D. Lipson, W. Miller, Jr, R. O'Connell, S. Opelman, W. Russell, H. Sheaffer, R. Simcox, S. Snedeker, J. Stone-Wynne, G. Tino, P. Wahl, J. Walter, P. Ward, D. Zisman, J. Mendez, A. Wurster; University of Pittsburgh, Pittsburgh, Pa-F. Sciurba, J. Luketich, C. Witt, G. Ayres, M. Donahoe, C. Fuhrman, R. Hoffman, J. Lacomis, J. Sexton, W. Slivka, D. Strollo, E. Sullivan, T. Simon, C. Wrona, G. Bauldoff, M. Brown, E. George, R. Keenan, T. Kopp, L. Silfies; University of Washington, Seattle, Wash-J. Benditt, D. Wood, M. Snyder, K. Anable, N. Battaglia, L. Boitano, A. Bowdle, L. Chan, C. Chwalik, B. Culver, T. Gillespy, D. Godwin, J.
Hoffman, A. Ibrahim, D. Lockhart, S. Marglin, K. Martay, P. McDowell, D. Oxorn, L. Roessler, M. Toshima, S. Golden.

Other participants included the following: Agency for Healthcare Research and Quality, Rockville, Md-L. Bosco, Y.-P. Chiang, C. Clancy, H. Handelsman; Centers for Medicare and Medicaid Services, Baltimore, Md-S. Sheingold, T. Carino, J. Chin, J. Farrell, K. McVearry, A. Norris, S. Shirey, C. Sikora; Coordinating Center, Johns Hopkins University, Baltimore, Md-S. Piantadosi, J. Tonascia, P. Belt, K. Collins, B. Collison, J. Dodge, M. Donithan, V. Edmonds, J. Fuller, J. Harle, R. Jackson, H. Koppelman, S. Lee, C. Levine, H. Livingston, J. Meinert, J. Meyers, D. Nowakowski, K. Owens, S. Qi, M. Smith, B. Simon, P. Smith, A. Sternberg, M. Van Natta, L. Wilson, R. Wise; Cost-Effectiveness Subcommittee-R. M. Kaplan, J. S. Schwartz, Y.-P. Chiang, M. C. Fahs, A. M. Fendrick, A. J. Moskowitz, D. Pathak, S. Ramsey, S. Sheingold, A. L. Shroyer, J. Wagner, R. Yusen; Cost-Effectiveness Data Center, Fred Hutchinson Cancer Research Center, Seattle, Wash-S. Ramsey, R. Etzioni, S. Sullivan, D. Wood, T. Schroeder, R. Smith, K. Berry, N. Myers; CT Scan Image Storage and Analysis Center, University of Iowa, Iowa City, Iowa-E. Hoffman, J. Cook-Granroth, A. Delsing, J. Guo, G. McLennan, B. Mullan, C. Piker, J. Reinhardt, J. Sieren, W. Stanford; Data and Safety Monitoring Board-J. A. Waldhausen, G. Bernard, D. DeMets, M. Ferguson, E. Hoover, R. Levine, D. Mahler, A. J. McSweeny, J. Wiener-Kronish, O.D. Williams, M. Younes; Marketing Center, Temple University, Philadelphia, $\mathrm{Pa}-$ G. Criner, C. Soltoff; Project Office, National Heart, Lung, and Blood Institute, Bethesda, Md-G. Weinmann, J. Deshler, D. Follmann, J. Kiley, M. Wu.

\section{Discussion}

Dr Joel D. Cooper (St Louis, Mo). Thank you for the opportunity, and thank you, Dr. Naunheim, for an excellent presentation and a chance to review the article. It is widely overlooked that the National Emphysema Treatment Trial (NETT) trial did have in advance a written hypothesis. The hypothesis stated "that patients who improve will have preoperative heterogeneously distributed emphysema involving the upper lobes predominantly." One of the disappointments of the NETT trial was the unwillingness to prospectively stratify patients according to that hypothesis to allow prospective analysis, and one of the major criticisms has been that most analyses now have had to be post hoc subgroup analyses, which detracts from the strength of the conclusions. To date, none of the NETT publications, including the presentation today, have stratified the patients according to the hypothesis of the trial, and therefore one question I have is this: When will the database be available so that the analysis of the group who are hypothesized to be lowest risk and greatest benefit will be available?

Our own single-institution population of about 300 patients is clearly a different set of patients: they have only heterogeneous distribution, with $92 \%$ of them having upper-lobe-predominant emphysema. I believe that is the reason why there is a disparity between the results we and others have obtained and those reported by the NETT, specifically reintubation in our series of $7 \%$ versus $22 \%$, tracheostomy in our series of $4 \%$ versus $8 \%$, and overall pulmonary morbidity of $14 \%$ instead of $30 \%$. I think this has nothing to do with the skill or the care of the patients. I think it has 
only to do with the selection of the patients. And therefore the second question is that I would like to ask your opinion of that.

I have always been a bit confused by the difference between homogenous distribution of emphysema and non-upper-lobepredominant emphysema. In the figures that you presented, $67 \%$ of patients were classified as having the upper-lobe-predominant pattern, but only $58 \%$ of all the patients were described as having a heterogeneous pattern. This means that many of the patients classified as having upper-lobe-predominant emphysema were also classified as homogenous rather than heterogeneous, and I wonder if you could help me understand that.

Your mortality risk showed that, by far, the greatest factor was non-upper-lobe-predominant emphysema (an odds ratio of 3). Have you any idea why this predictor did not hold up for your major pulmonary morbidity? Pulmonary morbidity was the major cause of death. You showed that mortality was related to it but not morbidity in terms of the distribution of the emphysema pattern.

Finally, previous NETT publications have identified exercise capacity as an important prognostic indicator to the point that some Medicare patients are now denied the operation on the basis of that discriminator. Do you have any idea why that discriminator, exercise capacity, did not fall out as a major predictor of morbidity and mortality in your analysis?

Thank you very much for the privilege.

Dr Naunheim. Thank you, Joel. The answer to your first question is that the database will be available to the public in the spring of 2006.

The premise of the NETT trial was to do a prospective randomized trial comparing medical versus surgical therapy for a wide variety of patients and not just those with upper-lobe heterogeneous disease. There is no doubt that the inclusion criteria within the NETT trial were broader and intentionally so than those used by Dr Cooper and some other investigators. The idea was not just to determine whether the procedure was going to be effective but also in what group of patients it would be effective or ineffective and contraindicated. Thus it is true that our patient population is more diverse than that of Dr Cooper and his colleagues and than those of other investigators in the field.

The disparity between results with regard to the incidence of tracheostomy, reintubation, pneumonia, and the like is indeed due to this difference in patient selection. First of all, our patients, because of the Medicare funding, were on average 5 years older than in other series, and as you know, in this ill patient subset 5 years is an eternity. Therefore our patients were indeed older, more ill, and more fragile and did have more homogenous disease.

The question of upper-lobe versus heterogeneous disease is one we have also asked. You said that $67 \%$ of the patients were classified as having upper-lobe-predominant emphysema and only $58 \%$ as heterogeneous, and that really has to do with the subjective radiologist's evaluation of the heterogeneity and of the predominance. This was purely subjective. We are hoping that eventually the computerized analysis will give us a better and more objective feel for who has upper-lobe predominance versus lower-lobe predominance and who has homogenous versus heterogeneous, but that full analysis has not been done yet.

The fourth question was why upper-lobe emphysema did not hold up for pulmonary morbidity, and that I honestly cannot answer. I would have thought that it would have because it seemed to be so consistent in both our first and second major publications, in which homogeneity proved to be critical. Therefore the fact that the distribution of emphysema was not significant as a predictor for pulmonary morbidity also is a nettlesome question for us. I do not have the answer for that.

Finally, why didn't exercise capacity hold up as a predictor? If you remember, the exercise capacity was reported in the midterm survival and functional outcome results in the primary NETT outcome trial paper. And the reason that exercise capacity appeared to be a significant predictor was not because the surgical patients mattered with regard to high or low exercise but more of the fact that the medical patients who had low exercise capacity - as you remember, that was the indicator for "good outcome"- those who had low exercise capacity in the medical group deteriorated and died so quickly that it made the surgical group look better by comparison. It had nothing to do with the surgical group itself in regard to exercise capacity but rather with the very fragile condition of the medical group who had poor exercise capacity, and that group deteriorated very rapidly and died at an increased rate. Therefore we did see exercise capacity as a predictor of outcome and survival but only in the long term and not in the short term.

\section{JTCVS On-Line Manuscript Submission and Review}

The Journal of Thoracic and Cardiovascular Surgery requires authors and reviewers to submit all new and revised manuscripts and reviews via Editorial Manager. Point your browser to http://jtcvs.editorialmanager.com, log in as author or reviewer (as appropriate), and follow the instructions provided.

To retrieve your username and password, click "Forget your password?" on the Editorial Manager log-in page.

If you have questions or experience problems uploading your manuscript or review, please contact the editorial office:

Telephone: 215-762-1854

E-mail: jtcvs@drexel.edu 